\title{
Simultaneous Identification and Quantification of Canrenone and 11- $\alpha$-Hydroxy-Canrenone by LC-MS and HPLC-UVD
}

\author{
Da-Ming Huang, ${ }^{1}$ Tian-Zhen Zhang, ${ }^{1}$ Feng-Jie Cui,, ${ }^{1}$ Wen-Jing Sun, ${ }^{1,2}$ Li-Ming Zhao, ${ }^{3}$ \\ Meng-Yi Yang, ${ }^{1}$ and Ya-Juan Wang ${ }^{1}$ \\ ${ }^{1}$ School of Food and Biological Engineering, Jiangsu University, 301\# Xuefu Road, Zhenjiang 212013, China \\ ${ }^{2}$ PARCHN Sodium Isovitamin C Co., Ltd, Xingangshan Town, Dexing 334221, China \\ ${ }^{3}$ Department of Respiratory Disease, Changzheng Hospital, Second Military Medical University, 415 Fengyang Road, \\ Shanghai 200003, China \\ Correspondence should be addressed to Feng-Jie Cui, fengjiecui@163.com and Li-Ming Zhao, 1976zlm@163.com
}

Received 24 August 2011; Accepted 20 September 2011

Academic Editor: Dobromir Dobrev

Copyright (๑) 2011 Da-Ming Huang et al. This is an open access article distributed under the Creative Commons Attribution License, which permits unrestricted use, distribution, and reproduction in any medium, provided the original work is properly cited.

A procedure for simultaneous identification and quantification of canrenone and its biotransformed product 11- $\alpha$-hydroxycanrenone by high-performance liquid chromatography with ultraviolet detector (HPLC-UVD) and mass spectrometry (LC-MS) methods was proposed. The optimal determination variables on the HPLC-UVD or LC-MS coupled with a ZORBAX Eclipse XDBC18 column $(150 \mathrm{~mm} \times 4.6 \mathrm{~mm}, 5 \mu \mathrm{m})$ were set as follows: detection wavelength of $280 \mathrm{~nm}$, mobile phase of water and methanol gradient elution, temperature for the chromatographic column of $30^{\circ} \mathrm{C}$, flow rate of mobile phase of $0.8 \mathrm{~mL} / \mathrm{min}$, sample injection volume of $5 \mu \mathrm{L}$, and elution time of $40 \mathrm{~min}$. The MS conditions were set as follows: the flow rate of sheath gas, aux gas, and sweep gas were kept at $35 \mathrm{arb}, 5 \mathrm{arb}$, and $0 \mathrm{arb}$, respectively. The temperature of capillary was held at $300^{\circ} \mathrm{C}$, and capillary voltage was set at $30.00 \mathrm{~V}$. Tube lens were performed at $100.00 \mathrm{~V}$. The proposed method was validated by linearity $\left(r^{2} \geq 0.9910\right)$, average recovery $(94.93 \%$, RSD1.21\%), precision (RSD $\leq 1.31 \%$ ), limit of detection, and limit of quantification (LOD $0.1 \sim 0.12 \mathrm{mg} / \mathrm{L}$, LOQ $0.5 \sim 0.67 \mathrm{mg} / \mathrm{L}$ ), which proved to be affordable for simultaneously determining canrenone and its bio-transformed product 11- $\alpha$-hydroxy-canrenone.

\section{Introduction}

Canrenone (CR), a cardiovascular drug, a sort of steroid, is spironolactone's major metabolite and has been widely used as a nonselective aldosterone receptor antagonist clinically to treat heart failure, high blood pressure, edema, liver ascites, and other cardiovascular diseases $[1,2]$. However, canrenone also has the significant side effects including ataxia, mental confusion, and hirsutism. To enhance curative effect and reduce those side effects, hydroxylation and/or nitration steps were developed to synthesize its derivatives [3, 4]. Eplerenone is the first agent in a new class of drugs known as the selective aldosterone-receptor antagonists (SARAs), and has a 15- to 20-fold lower affinity for the mineralocorticoid receptor; however, fewer adverse events occur due to its specific binding to aldosterone [5-8]. Eplerenone can be semi- chemically synthesized from canrenone, which involves the $11-\alpha$-hydroxylation as the first step and one of the most key steps $[9,10]$. The production of 11- $\alpha$-hydroxy-canrenone by the 11- $\alpha$-hydroxylation reaction can be conducted by chemical synthesis or microbial transformation (Figure 1). Chemical synthesis will lead to some problems including low stereoand region-selectivity, strict reaction condition environmental pollution, and complicated and expensive production processes, while microbial transformation process can be considered as a "green" producing alternative that overcomes the above problems from chemical synthesis [11-14].

The hydroxylation of steroids by fungal biocatalysts has been known for many years, this procedure remains one of the most useful preparative methods for the introduction of hydroxyl groups at sites of the steroid nucleus remote from other functionality, and the value of microbial steroid 


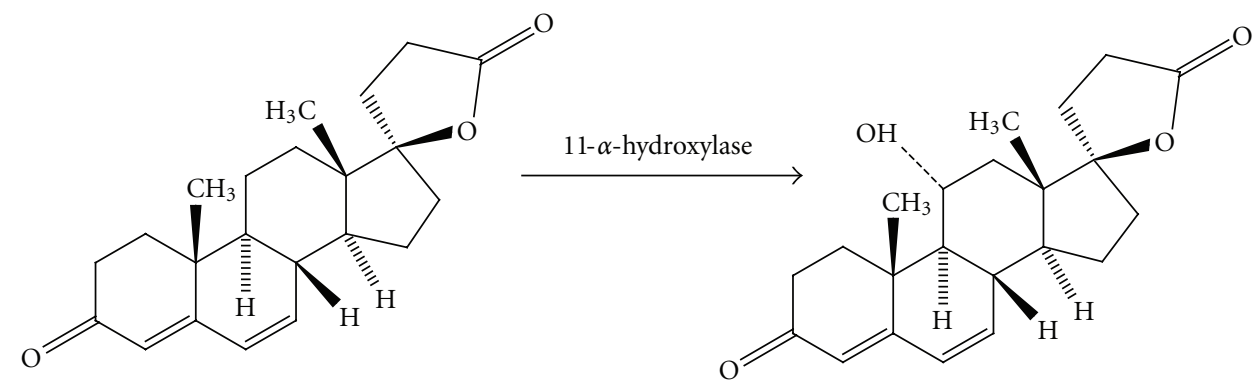

FIGURE 1: 11- $\alpha$-hydroxylation of canrenone by microbial transformation.

hydroxylation in the preparation of pharmacologically active steroids is well established. In our primary experiments, a fungus of Rhizopus sp UJS-0602 was screened for producing the 11- $\alpha$-hydroxy-canrenone from canrenone. However, a key step of proposing a reliable assay method for determining canrenone and 11- $\alpha$-hydroxy-canrenone was necessary to evaluate productivity of 11- $\alpha$-hydroxy-canrenone, consuming rate of canrenone, and biotransformating yield. However, few references were provided for simultaneously determining 11- $\alpha$-hydroxy-canrenone and canrenone in biotransformation by high-performance liquid chromatography (HPLC), but few related works dealing with the simultaneous quantitation of spironolactone and canrenone in human [15$18]$ and rat [19] plasma samples, in urine samples [20, 21], or in tablets [22]. Similar structure between 11- $\alpha$-hydroxycanrenone and canrenone also increases the difficulties for accurate determination of the two substances by the other methods such as colorimetry or thin-layer chromatography (TLC).

The aim of the present study was to propose a simple, quick, accurate, and feasible determining procedure for simultaneous identification and quantification of canrenone and 11- $\alpha$-hydroxy-canrenone by two novel reversed-phase LC-MS and HPLC-UV.

\section{Experimental Chemicals and Reagents}

Standard canrenone and 11- $\alpha$-hydroxy-canrenone were purchased from the Fisher Scientific International Inc. (Hampton, New Hampshire, USA). For microbial transformation, substrate canrenone with purity $\geq 97 \%$ was purchased from TaiYuan RHF Co. (Shanxi, China). Methanol (Tedia, Baker, USA) was of HPLC grade and all other chemicals were of analytical reagent grade.

\section{Microbial Transformation Procedure}

Microorganism Rhizopus sp UJS-0602 was activated on the PDA slants for $5 \mathrm{~d}$ at $28^{\circ} \mathrm{C}$, then washed out with sterile water and transferred to fresh liquid medium a $500 \mathrm{~mL}$ erlenmeyer flask with $100 \mathrm{~mL}$ liquid culture medium, and cultured for $33 \mathrm{~h}$ at $28^{\circ} \mathrm{C}$ with the shaking rate of $160 \mathrm{r} / \mathrm{min}$. Further, the substrate canrenone dissolved in dimethyl formamide (DMF;
$3.6 \mathrm{~g} / \mathrm{l})$ was added into the cultured broth and transformed for another 48 hours at the same culture conditions.

3.1. Sample Preparation. Mixed standard stock solution of canrenone and 11- $\alpha$-hydroxy-canrenone $(10 \mathrm{~g} / \mathrm{L})$ was prepared by accurately weighing $10 \mathrm{mg}$ of canrenone and 11$\alpha$-hydroxy-canrenone standards, dissolving into $1 \mathrm{~mL}$ of HPLC-grade methanol. The working standard solutions were prepared by diluting the mixed standard solution with methanol to a series of proper concentrations $(3 \mathrm{~g} / \mathrm{L}, 1.5 \mathrm{~g} / \mathrm{L}$, $0.75 \mathrm{~g} / \mathrm{L}, 0.3 \mathrm{~g} / \mathrm{L}$, and $0.1 \mathrm{~g} / \mathrm{L}$ ). The standard stock solution and working solutions were all stored at $4^{\circ} \mathrm{C}$.

The microbial transformed broth was filtered into two fractions of mycelia and filtrate which were further extracted with ethyl acetate in an amount five-times its volume for three times, respectively. The microbial transformed sample was obtained by collecting and concentrating the organic phases to dry, redissolving, and diluting with methanol to volume of $100 \mathrm{~mL}$ for HPLC analysis.

3.2. LC-MS and HPLC-UV Analysis. The LC-MS qualitative analysis was carried out on an ion trap Thermo LXQ Finnigan SURYEYOR (USA). The separation was performed using a ZORBAX Eclipse XDB-C18 column $(150 \mathrm{~mm} \times 4.6 \mathrm{~mm}$, $5 \mu \mathrm{m}$ ) supplied by Agilent Technologies, USA. The qualitative gradient elution system consisted of methanol (Mobile Phase $A$ ) and water (Mobile Phase B). The separation was achieved using the following gradient program: $0-40 \mathrm{~min}$ (10\% 50\% Mobile Phase A), 40-60 min (50\% 100\% Mobile Phase A). The flowrate was set at $0.8 \mathrm{~mL} / \mathrm{min}$ and the samples were injected automatically $(5.0 \mu \mathrm{L}$ of each other). The column was thermostatically controlled at $30^{\circ} \mathrm{C}$ and the chromatogram was monitored at $280 \mathrm{~nm}$. The flow rate of sheath gas, aux gas, and sweep gas were kept at 35 arb, 5 arb, and $0 \mathrm{arb}$, respectively. The temperature of capillary was held at $300^{\circ} \mathrm{C}$ and capillary voltage was set at $30.00 \mathrm{~V}$. Tube lens were performed at $100.00 \mathrm{~V}$.

The HPLC-UV analysis was carried out on a Waters Alliance LC-20AT (SHIMADZU, Japan) liquid chromatograph connected to a model 2996 (DAD) diode array detector and controlled by LC Driver Ver.2.0 for Waters Empower software. The optimized gradients employed were 0-40 min, $10 \% \sim 100 \%$ methanol, and $90 \% \sim 0 \%$ water. The column and other chromatographic conditions were the same as 
those used for the LC-MS analysis. Data were processed using Waters Empower software.

3.3. Calibration Curves. The working standard solutions were brought to room temperature and an aliquot of $5.0 \mu \mathrm{L}$ was injected into HPLC for construction of calibration curves. The column and chromatographic condition were the same as described in Section 3.3 of HPLC-UV. The five concentrations of working standard solutions were analyzed in triplicate and calculating the calibration curves were calculated by linear regression of the double logarithmic plots of the peak area versus the concentration of the working standard solution injected.

The linearity was determined by the correlation coefficients of the analytical curves generated by injections of the working solutions at five concentration levels. In the method for quantification of canrenone and 11- $\alpha$-hydroxycanrenone in microbial transformation fluid, the analytical curves were constructed in triplicate by diluting the mixed standard solutions with methanol, which resulted in the final concentrations of $3 \mathrm{~g} / \mathrm{L}, 1.5 \mathrm{~g} / \mathrm{L}, 0.75 \mathrm{~g} / \mathrm{L}, 0.3 \mathrm{~g} / \mathrm{L}$, and $0.1 \mathrm{~g} / \mathrm{L}$.

3.4. Accuracy. Standard addition method was performed to evaluate the accuracy of the HPLC method. The procedure was summarized as follows: to determine $1 \mathrm{~mL}$ sample solution with the same concentration prepared in Section 3.1 for 5 parts accurately, and $1 \mathrm{~mL}$ of $10 \%$ canrenone standard solution was added to each sample solution. The prepared 5 samples above were analyzed in turn by HPLC-UV. The average recoveries were calculated by the following formula:

$$
\text { Recovery }(\%)=\frac{\text { Canrenone amount found }(\mathrm{g})-\text { Original Canrenone amount in sample solution }(\mathrm{g})}{\text { Canrenone added amount }(\mathrm{g})} \times 100 \% \text {, }
$$

with relative standard deviations $(\mathrm{RSD} \%)=(\mathrm{SD} /$ mean $) \times$ $100 \%$.

3.5. Repeatability. For repeatability test, five independent analytical sample solutions from the same batch of sample were prepared in same procedures noted in Section 3.1, RSD\% values of the obtained contents of each analyte were used to estimate repeatability.

3.6. Precision and Intermediate Precision. The stability test was chosen to determine the precision of the HPLC-UV method. The same sample solution prepared in Section 3.1 was analyzed as described in Section 3.3 of HPLC-UV in 6 different hours: $0 \mathrm{~h}, 4 \mathrm{~h}, 8 \mathrm{~h}, 12 \mathrm{~h}, 18 \mathrm{~h}$, and $24 \mathrm{~h}$ throughout a day. Variations of the peak area were taken as the measures of precision and expressed as RSD\%. Intermediate precision was determined by analyzing the mixed standard solution with the same concentration employed in Section 3.1 continuously for 5 times. Precision was expressed in terms of RSD\%.

3.7. Limit of Detection (LOD) and Limit of Quantitation (LOQ). LOD and LOQ were estimated experimentally by injecting standard solutions of canrenone and 11- $\alpha$-hydroxycanrenone diluted in methanol under the above chromatographic conditions in Section 3.2 of HPLC-UV until the signal-to-noise ratio for the standards reached a $3: 1$ ratio for LOD and 10: 1 for LOQ.

\section{Results and Discussion}

4.1. Identification of Canrenone and 11- $\alpha$-Hydroxy-Canrenone by LC-MS. For the purpose of correct identification, an LCMS analysis was performed on standard under the LC-MS conditions. The previous chromatographic conditions for determination of the two sterols in microbial transformation fluid by LC-MS were used as the basis for mobile phase selection and optimization. Unfortunately, the reported gradient elution of methanol-water could not be applied to the separation of canrenone and 11- $\alpha$-hydroxy-canrenone. Under this circumstance, the gradient elution program was carefully adjusted and after several trials the new gradient program was selected until it permitted the best separation ability for the two sterols. Figure 2 shows that under the optimized LC-MS conditions, canrenone and 11- $\alpha$-hydroxycanrenone were separated and identified by analysing their mass spectra. The results of MS spectrogram are shown in Figure 2. Comparing the standards of 11- $\alpha$-hydroxylation of canrenone Figure 2(A) and canrenone Figure 2(B), the mass-to-charge ratios of each molecular ion peak $(\mathrm{M}+$ $\mathrm{H})$ were 357.4 and 341.4, respectively. According to the references, the molecular weight of 11- $\alpha$-hydroxylation of canrenone and canrenone are 356.4 and 340.4, which meant that the molecular weight of $11-\alpha$-hydroxylation is 16 more than canrenone. Hence, the hydroxylation of canrenone has occurred by the selected biotransforming strain Rhizopus $s p$ UJS-0602.

4.2. Quantitative Analysis of Canrenone and 11- $\alpha$-HydroxyCanrenone by HPLC-UV. The proposed LC-MS method was successfully applied to simultaneous determination of canrenone and 11- $\alpha$-hydroxy-canrenone in microbial transformation fluid. But it cost a lot of time under the LC-MS conditions described in Section 3.3. The optimal condition for the extraction by HPLC-UV of canrenone and 11- $\alpha$ hydroxy-canrenone was selected and presented in details in Section 3.3.

As shown in Figure 3, canrenone and 11- $\alpha$-hydroxy-canrenone were comprehensively separated and their retention times were at $29 \mathrm{~min}$ and $33 \mathrm{~min}$ severally. From the picture, we can see that the peak of canrenone at 33 min reduced radically after transformation reaction when the peak of 11- $\alpha$-hydroxy-canrenone at $29 \mathrm{~min}$ raised sharply, which 


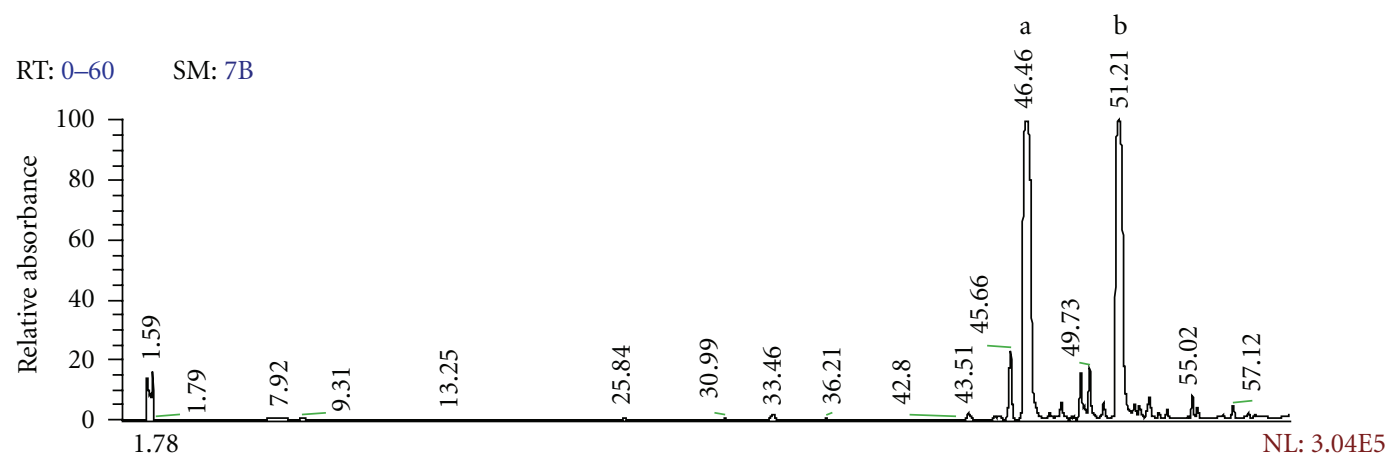

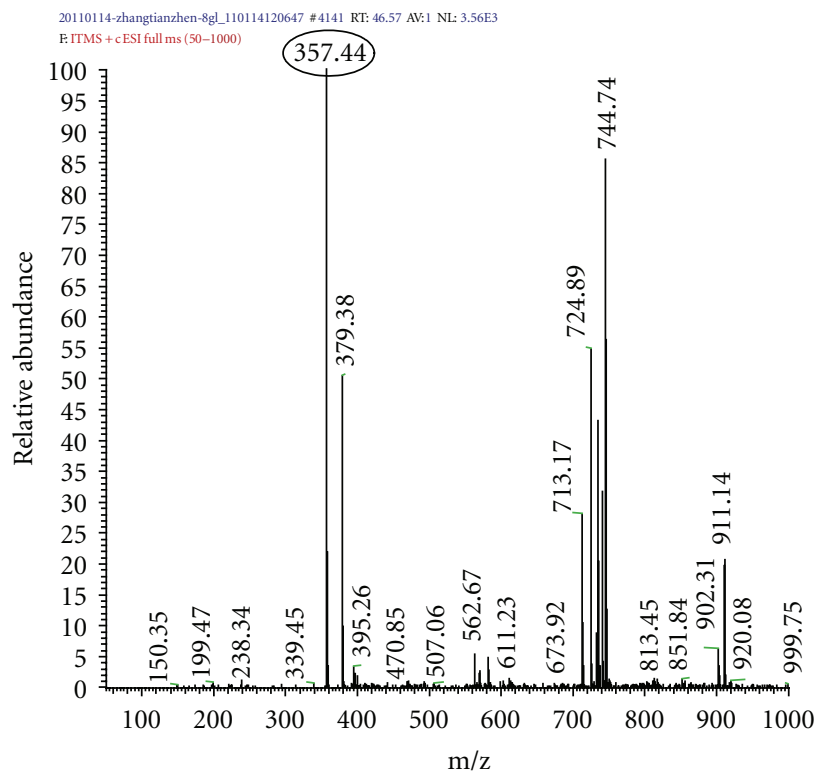

(A)

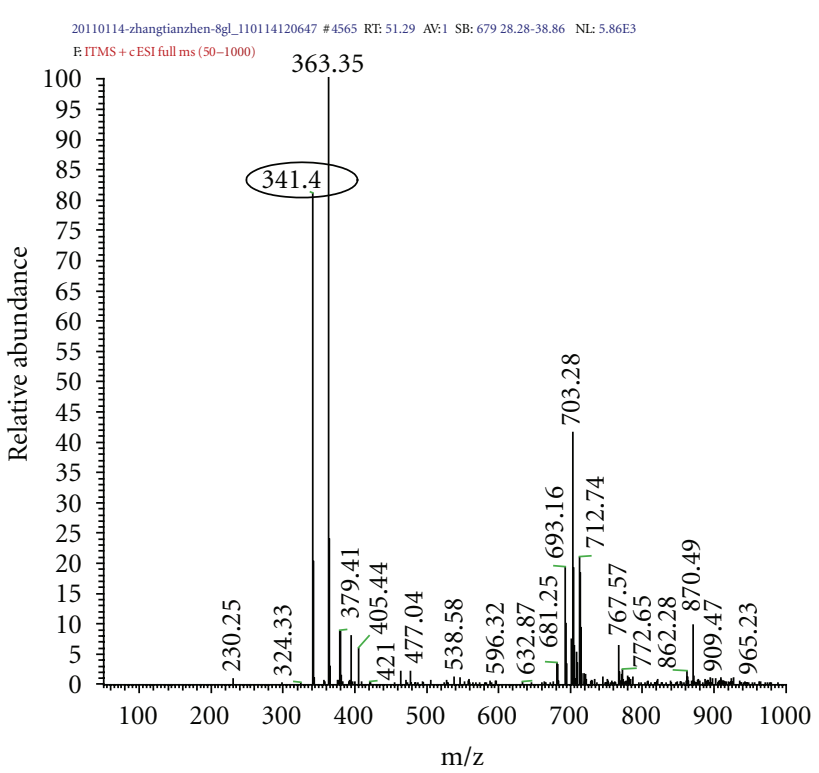

(B)

FIgURE 2: LC-MS chromatograms of mixed standards (a) and (b) in negative-ion mode. HPLC was performed on a ZORBAX Eclipse XDBC18 column $(150 \mathrm{~mm} \times 4.6 \mathrm{~mm}, 5 \mu \mathrm{m})$ at the column temperature of $30^{\circ} \mathrm{C}$. The separation was achieved using the following gradient program: $0-40 \mathrm{~min}$ (10\% 50\% methanol), 40-60 $\mathrm{min}(50 \% \sim 100 \%$ methanol). The flowrate was at $0.8 \mathrm{~mL} / \mathrm{min}$ and the sample injection volume was 5.0 $\mu \mathrm{L}$. Peak assignments: (a) canrenone; (b) 11- $\alpha$-hydroxy-canrenone. MS spectrograms (A) and (B) stand for the molecular weight of the peak (a) and (b) at 357.44 and $341.40 \mathrm{amu}$, respectively.

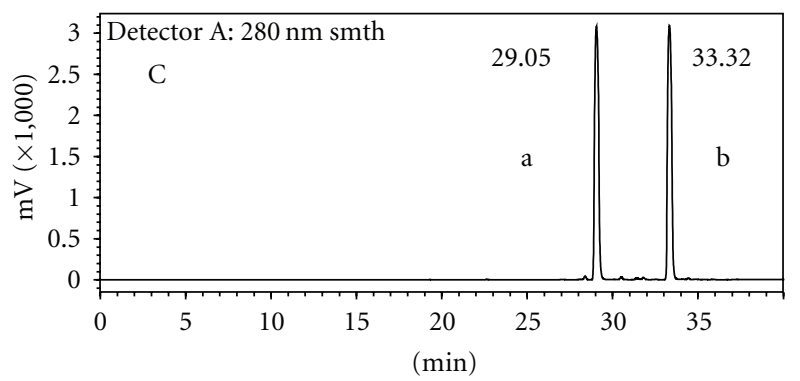

(a)

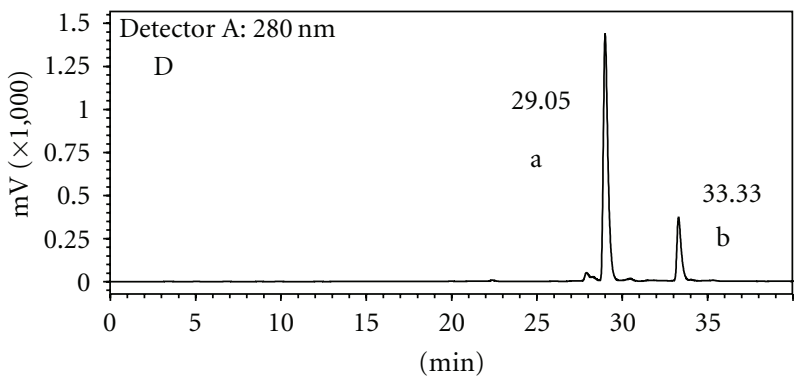

(b)

FIgURE 3: Typical HPLC-UV chromatogram $(\lambda=280 \mathrm{~nm})$ of $(C)$ mixed standards of canrenone and 11- $\alpha$-hydroxy-canrenone and (D) samples extracted from microbial transformed fluid. The quantitative gradient elution system consist of methanol and water. The gradient program: $0-40 \mathrm{~min}, 10 \% \sim 100 \%$ methanol, and 90\% 0\% water. For other chromatographic conditions were the same as those in Section 3.3. Peak assignments: (a) canrenone; (b) 11- $\alpha$-hydroxy-canrenone. 


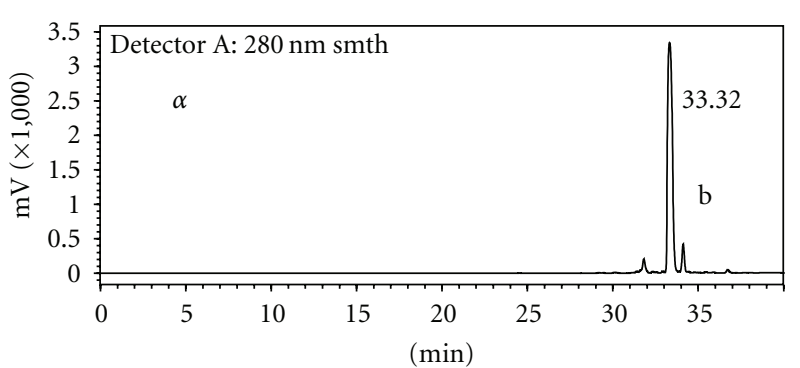

(a)

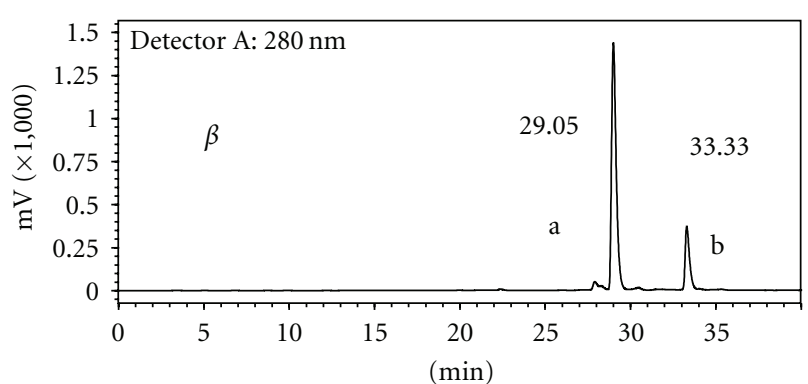

(b)

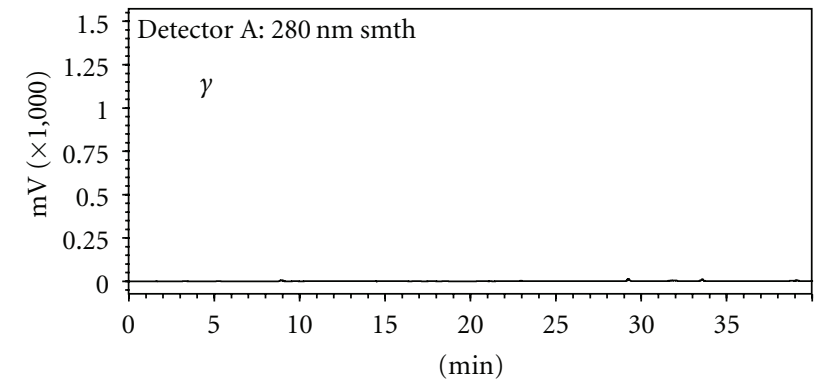

(c)

FIGURE 4: Representative chromatograms of substrate canrenone before transformation $(\alpha)$, and of bioconversion broth obtained after conversion for $48 \mathrm{~h}(\beta)$, and of blank $(\gamma)$ peaks: $\mathrm{a}=$ canrenone, $\mathrm{b}=11$ - $\alpha$-hydroxy-canrenone.

TABLE 1: Parameters of the analytical curves, LOD, and LOQ for canrenone and 11- $\alpha$-hydroxy-canrenone quantification by HPLC-UV.

\begin{tabular}{|c|c|c|c|c|c|}
\hline Standard & $\begin{array}{c}\text { Concentration } \\
\text { range }(\mathrm{g} / \mathrm{L})\end{array}$ & Calibration curve ${ }^{\mathrm{a}}$ & $\begin{array}{c}\text { Correlation } \\
\text { coefficients }\left(r^{2}\right)\end{array}$ & $\mathrm{LOD}^{\mathrm{b}}$ & $\mathrm{LOQ}^{\mathrm{c}}$ \\
\hline Canrenone & $0.1 \sim 3.0$ & $y=0.4587+1.2879 x$ & 0.9910 & $0.1 \mathrm{mg} / \mathrm{L}$ & $0.5 \mathrm{mg} / \mathrm{L}$ \\
\hline 11- $\alpha$-hydroxy-canrenone & $0.1 \sim 3.0$ & $y=0.3681+1.2274 x$ & 0.9928 & $0.12 \mathrm{mg} / \mathrm{L}$ & $0.67 \mathrm{mg} / \mathrm{L}$ \\
\hline
\end{tabular}

$y$ and $x$ stand for logarithmic values of peak area and concentration $(\mathrm{g} / \mathrm{L})$, respectively.

${ }^{b}$ Limit of detection $(\mathrm{S} / \mathrm{N}=3)$.

${ }^{\mathrm{c}}$ Limit of quantification $(\mathrm{S} / \mathrm{N}=10)$.

demonstrated that the transformation reaction through microorganism was successfully completed.

\subsection{Validation of the Proposed Method}

4.3.1. Linearity, $L O D$, and $L O Q$. According to the data in Table 1, acceptable results of the regression analysis, the correlation coefficients $\left(r^{2}\right)$, LODs, and LOQs were obtained for all the analytes: both of the calibration curves showed good linear regression $\left(r^{2} \geq 0.9911\right)$ within the test range; the LODs and LOQs of the two sterols were in the range of $0.1 \sim 0.12 \mathrm{mg} / \mathrm{L}$ and $0.5 \sim 0.67 \mathrm{mg} / \mathrm{L}$, respectively.

Accuracy, Repeatability, Precision, and Intermediate Precision. Table 2 presents that the developed method had good accuracy with the overall recovery of $91.75-97.94 \%$, with the RSD $1.21 \%$. The results of the repeatability test shown in Table 3 demonstrated that the developed assay was reproducible $(\mathrm{RSD}=1.21 \%)$, and the intermediate precision of this method was also acceptable $(\mathrm{RSD}=1.37 \%$ and $1.21 \%)$. The stability test was chosen to determine the precision of the HPLC-UV method. For the stability test
(Table 4), the analysis was performed by injecting the same sample solution prepared in Section 3.2 in 6 different hours: $0 \mathrm{~h}, 4 \mathrm{~h}, 8 \mathrm{~h}, 12 \mathrm{~h}, 18 \mathrm{~h}$, and $24 \mathrm{~h}$ throughout a day, and it was found to be rather stable daylong (RSD $=1.03 \%$ and $1.35 \%)$. These results indicated that the HPLC-UVD method is accurate, precise, and sensitive for quantitative determination of canrenone and 11- $\alpha$-hydroxy-canrenone in the microbial transformation fluid.

4.4. Application. The method was used to determine biotransformation broth of canrenone and $11 \alpha$-hydroxy-canrenone obtained after transformation simultaneously. Figure 4 showed the representative chromatograms of substrate canrenone before transformation (Figure $4 \alpha$ ), and of bioconversion broth obtained after conversion for $48 \mathrm{~h}$ (Figure $4 \beta$ ), and of blank (Figure $4 \gamma$ ). Comparing with the representative chromatograms of standard solution by LCMS/HPLC-UVD shown in Figures 2 and 3(C), it could be seen that canrenone and $11 \alpha$-hydroxy-canrenone were eluted at $29.05 \mathrm{~min}$ and $33.33 \mathrm{~min}$ without carryover, and $11-\alpha-$ hydroxy-canrenone existed as product in biotransformation system. No other impurity peaks were found in Figure 3(C) 
TABLE 2: Accuracy of HPLC-UV method for canrenone.

\begin{tabular}{lccccc}
\hline Samples & Original $(\mathrm{g})$ & Added $(\mathrm{g})$ & Found $(\mathrm{g})$ & Recovery $^{\mathrm{a}}(\%)$ & Mean Recovery $(\%)^{\text {RSD }^{\mathrm{b}}(\%)}$ \\
\hline 1 & 0.0014 & 0.0097 & 0.0107 & 95.88 & 91.75 \\
2 & 0.0015 & 0.0097 & 0.0104 & 94.85 & 94.93 \\
3 & 0.0014 & 0.0097 & 0.0106 & 97.94 & 1.21 \\
4 & 0.0013 & 0.0097 & 0.0108 & 93.81 & \\
5 & 0.0014 & 0.0097 & 0.0105 & & \\
\hline
\end{tabular}

${ }^{\mathrm{a}}$ Recovery $(\%)=(($ canrenone amount found-original canrenone amount in sample solution $) /$ canrenone added amount $) \times 100 \%$.

$\mathrm{b}(\mathrm{RSD} \%)=($ S.D. $/$ mean $) \times 100 \%$.

TABLE 3: Repeatabilities and intermediate precisions of HPLC-UV method for canrenone and 11- $\alpha$-hydroxy-canrenone.

\begin{tabular}{|c|c|c|c|c|c|c|c|c|}
\hline \multirow{3}{*}{ Samples } & \multicolumn{4}{|c|}{ Repeatability $(n=5)$} & \multicolumn{4}{|c|}{ Intermediate precision $^{\mathrm{f}}(n=5)$} \\
\hline & \multicolumn{2}{|c|}{ Content $(\mathrm{g} / \mathrm{L})$} & \multicolumn{2}{|c|}{$\mathrm{RSD} \%$} & \multicolumn{2}{|c|}{ Content $(\mathrm{g} / \mathrm{L})$} & \multicolumn{2}{|c|}{$\mathrm{RSD} \%$} \\
\hline & $\mathrm{a}$ & $\mathrm{b}$ & a & $\mathrm{b}$ & $\mathrm{a}$ & $\mathrm{b}$ & a & $\mathrm{b}$ \\
\hline 1 & 1.3813 & 1.8343 & & & 2.2379 & 2.2127 & & \\
\hline 2 & 1.3726 & 1.8387 & & & 2.2267 & 2.1567 & & \\
\hline 3 & 1.3792 & 1.8814 & 0.99 & 1.03 & 2.2140 & 2.1479 & 1.37 & 1.21 \\
\hline 4 & 1.4029 & 1.8471 & & & 2.2725 & 2.1704 & & \\
\hline 5 & 1.4011 & 1.8609 & & & 2.2086 & 2.1914 & & \\
\hline
\end{tabular}

${ }^{a}$ Canrenone.

b 11- $\alpha$-hydroxy-canrenone.

eFive samples was analyzed, and contents of each solution were used to access repeatability.

${ }^{\mathrm{f}}$ The mixed standard solutions with the same concentration were analyzed, and their contents were used to access intermediate precision.

TABLE 4: Precisions of HPLC-UV method for canrenone and 11- $\alpha$-Hydroxy-canrenone.

\begin{tabular}{|c|c|c|c|c|c|c|}
\hline \multirow{2}{*}{ Time (h) } & \multicolumn{2}{|c|}{ Content (g/L) } & \multicolumn{2}{|c|}{ Mean content $(\mathrm{g} / \mathrm{L})$} & \multicolumn{2}{|c|}{ RSD\% } \\
\hline & $\mathrm{a}$ & $\mathrm{b}$ & $\mathrm{a}$ & $\mathrm{b}$ & $\mathrm{a}$ & $\mathrm{b}$ \\
\hline 0 & 1.3813 & 1.8343 & \multirow{6}{*}{1.3784} & \multirow{6}{*}{1.8664} & \multirow{6}{*}{1.03} & \multirow{6}{*}{1.35} \\
\hline 4 & 1.3842 & 1.9036 & & & & \\
\hline 8 & 1.3930 & 1.8679 & & & & \\
\hline 12 & 1.3516 & 1.8650 & & & & \\
\hline 18 & 1.3760 & 1.8834 & & & & \\
\hline 24 & 1.3844 & 1.8444 & & & & \\
\hline
\end{tabular}

${ }^{\mathrm{a}}$ Canrenone.

b 11- $\alpha$-hydroxy-canrenone.

and Figure 3(D). The obtained results indicated that the detecting results were satisfactory, and the proposed method could be applied to the following researches of biotransformation of canrenone to 11- $\alpha$-hydroxy-canrenone in our laboratory.

\section{Conclusions}

In this study, an HPLC coupled with MS and UVD method has been proposed for simultaneous identification and quantification of canrenone and 11- $\alpha$-hydroxy-canrenone in the microbial transformation broth. The parameters evaluated here demonstrated that the methods offer good specificity, linearity, accuracy, and precision within acceptable limits while the LODs and LOQs confirmed the efficiency of the methodologies in quantifying low concentrations of sterols. These results are definitely helpful to control the quality of canrenone and 11- $\alpha$-hydroxy-canrenone, and provide a scientific basis for the search for the improvement the quality of sterols products and transformation efficiency in the production.

\section{Acknowledgments}

This paper was financially supported by funding from the National Natural Science Foundation of China (NSFC 31101269), International Foundation for Science Grant Program (no. F 4930-1), Technological Research and Development Program of Zhenjiang City (GY2011006), Jiangxi Provincial Engineering and Technology Research Center for Food Additives Bioproduction; Research Foundation for Advanced Talents of Jiangsu University (08JDG029), Leaders of Disciplines and Science Cultivation Program of Jiangxi Province (2008DD00600), Science and Technology 
Program of Jiangxi Province (2010DQB00800 and no. (2008147), Science and Technology Platform Construction Program of Jiangxi Province, Priority Academic Program Development of Jiangsu Higher Education Institutions, and Student Research Grant Program of Jiangsu University (no. Y10A075).

\section{References}

[1] S. Werner, M. Christine, B. Eber, E. Barbara et al., "Intoxication due to negative canrenone interference in digoxin drug monitoring," The Lancet, vol. 354, no. 9185, pp. 1176-1177, 1999.

[2] B. Marrs, S. Delagrave, and D. Murphy, "Novel approaches for discovering industrial enzymes," Current Opinion in Microbiology, vol. 2, no. 3, pp. 241-245, 1999.

[3] C. L. Preisig, J. A. Laakso, U. M. Mocek, P. T. Wang, J. Baez, and G. Byng, "Biotransformations of the cardiovascular drugs mexrenone and canrenone," Journal of Natural Products, vol. 66, no. 3, pp. 350-356, 2003.

[4] R. Megges, J. Weiland, B. Undeutsch, H. Büchting, and R. Schön, "The nitration of canrenone with acetic anhydride/nitric acid," Steroids, vol. 62, no. 12, pp. 762-766, 1997.

[5] E. G. McMahon, "Recent studies with eplerenone, a novel selective aldosterone receptor antagonist," Current Opinion in Pharmacology, vol. 1, no. 2, pp. 190-196, 2001.

[6] E. D. Burgess, Y. Lacourciere, L. M. Ruilope-Urioste et al., "Long-term safety and efficacy of the selective aldosterone blocker eplerenone in patients with essential hypertension," Clinical Therapeutics, vol. 25, no. 9, pp. 2388-2404, 2003.

[7] K. L. Davis and J. M. Nappi, "The cardiovascular effects of eplerenone, a selective aldosterone-receptor antagonist," Clinical Therapeutics, vol. 25, no. 11, pp. 2647-2668, 2003.

[8] W. B. White, A. A. Carr, S. Krause, R. Jordan, B. Roniker, and W. Oigman, "Assessment of the novel selective aldosterone blocker eplerenone using ambulatory and clinical blood pressure in patients with systemic hypertension," The American Journal of Cardiology, vol. 92, no. 1, pp. 38-42, 2003.

[9] S. Gladiali, A. Gallotti, R. Vitali, and R. Gardi, "Facilitated reduction of 11-ketone in corticosteroid 17,21-diacetates," Chemistry and Industry, vol. 24, pp. 982-983, 1977.

[10] M. Nussium and F. Sondheimer, "New synthesis of 11-oxygenated steroids," Chemistry \& Industry, vol. 4, pp. 400-401, 1960.

[11] L. X. Du, S. J. Jia, and F. P. Lu, "Morphological changes of Rhizopus chinesis 12 in submerged culture and its relationship with antibiotic production," Process Biochemistry, vol. 38, no. 12, pp. 1643-1646, 2003.

[12] A. J. Reyes, W. P. Leary, P. Crippa et al., "The aldosterone antagonist and facultative diuretic eplerenone: a critical review," European Journal of Internal Medicine, vol. 16, no. 1, pp. 3-11, 2005.

[13] E. Gharaee Fathabad, M. TabatabaeiYazdi, M. A. Faramarzi et al., "Biotransformation of Hydroeortisone by Neurospora crassa," Journal of Sciences, Islamic Republic of Iran, vol. 17, no. 4, pp. 309-312, 2006.

[14] A. Romano, D. Romano, E. Ragg et al., "Steroid hydroxylations with Botryodiplodia malorum and Colletotrichum lini," Steroids, vol. 71, no. 6, pp. 429-434, 2006.

[15] D. I. Sora, S. Udrescu, F. Albu, V. David, and A. Medvedovici, "Analytical issues in HPLC/MS/MS simultaneous assay of furosemide, spironolactone and canrenone in human plasma samples," Journal of Pharmaceutical and Biomedical Analysis, vol. 52, no. 5, pp. 734-740, 2010.
[16] J. M. Sandall, J. S. Millership, P. S. Collier, and J. C. McElnay, "Development and validation of an HPLC method for the determination of spironolactone and its metabolites in paediatric plasma samples," Journal of Chromatography B, vol. 839, no. 1-2, pp. 36-44, 2006.

[17] H. Zhang and J. T. Stewart, "Liquid chromatographic determination of canrenone in human serum using solid-phase extraction," Journal of Pharmaceutical and Biomedical Analysis, vol. 11, no. 11-12, pp. 1341-1344, 1993.

[18] A. Jankowski, A. Skorek-Jankowska, and H. Lamparczyk, "Simultaneous determination of spironolactone and its metabolites in human plasma," Journal of Pharmaceutical and Biomedical Analysis, vol. 14, no. 8-10, pp. 1359-1365, 1996.

[19] A. M. Kaukonen, P. Vuorela, H. Vuorela, and J. P. Mannermaa, "High-performance liquid chromatography methods for the separation and quantitation of spironolactone and its degradation products in aqueous formulations and of its metabolites in rat serum," Journal of Chromatography A, vol. 797, no. 1-2, pp. 271-281, 1998.

[20] E. Martin, A. I. Jimenez, O. Hernandez et al., "Simultaneous kinetic spectrophotome- tric determination of spironolactone and canrenone in urine using partial least-squares regression," Talanta, vol. 49, no. 1, pp. 143-154, 1999.

[21] R. Herraez-Hernandez, E. Soriano-Vega, and P. CampinsFalco, "High-performance liquid chromatographic determination of spironolactone and its major metabolite canrenone in urine using ultraviolet detection and column-switching," Journal of Chromatography B, vol. 658, no. 2, pp. 303-310, 1994.

[22] F. De Croo, W. Van den Bossche, and P. De Moerloose, "Simultaneous quantitative determination of butizide, potassium canrenoate and canrenone in tablets by high-performance liquid chromatography," Journal of Chromatography A, vol. 354, pp. 367-373, 1986. 

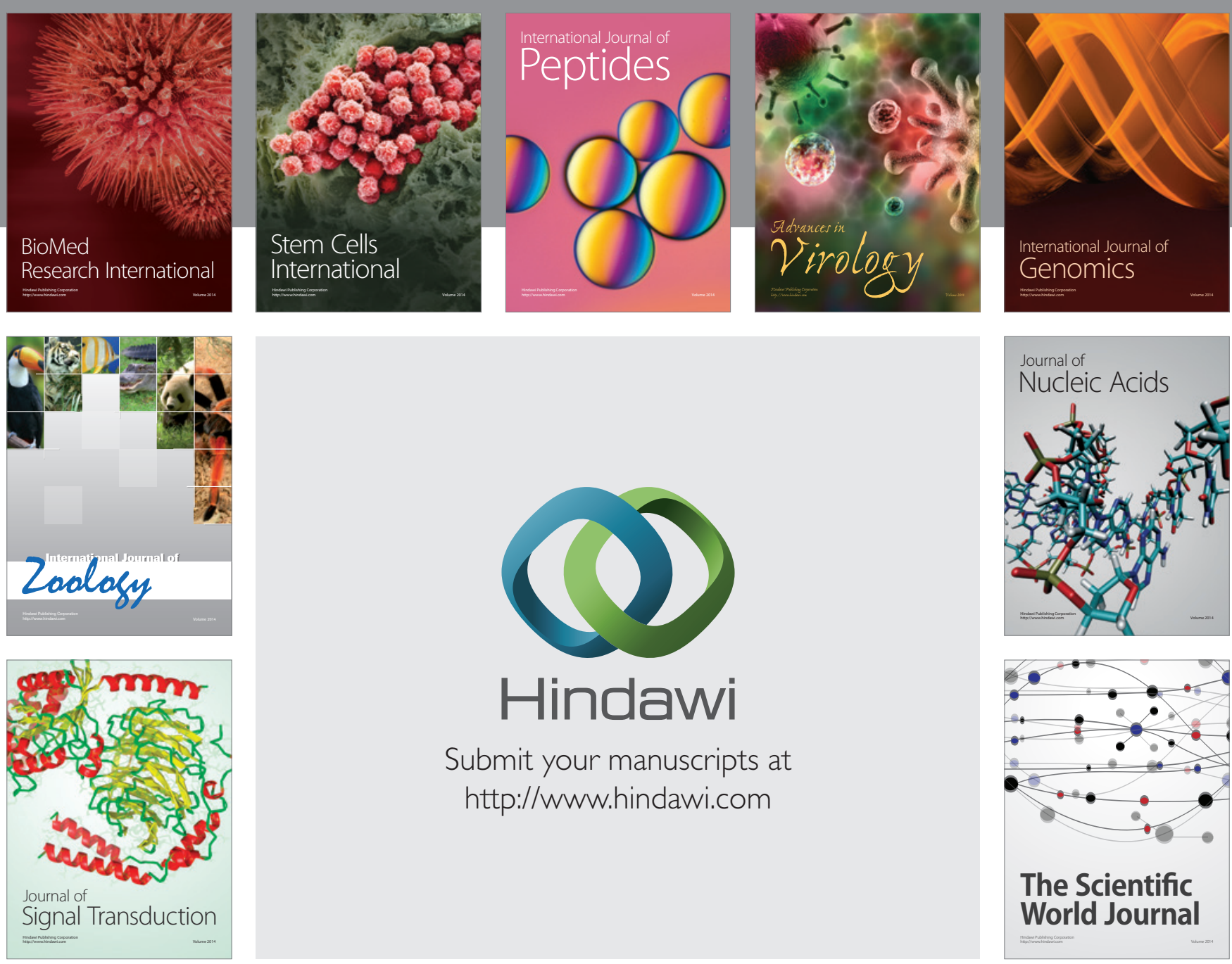

Submit your manuscripts at

http://www.hindawi.com
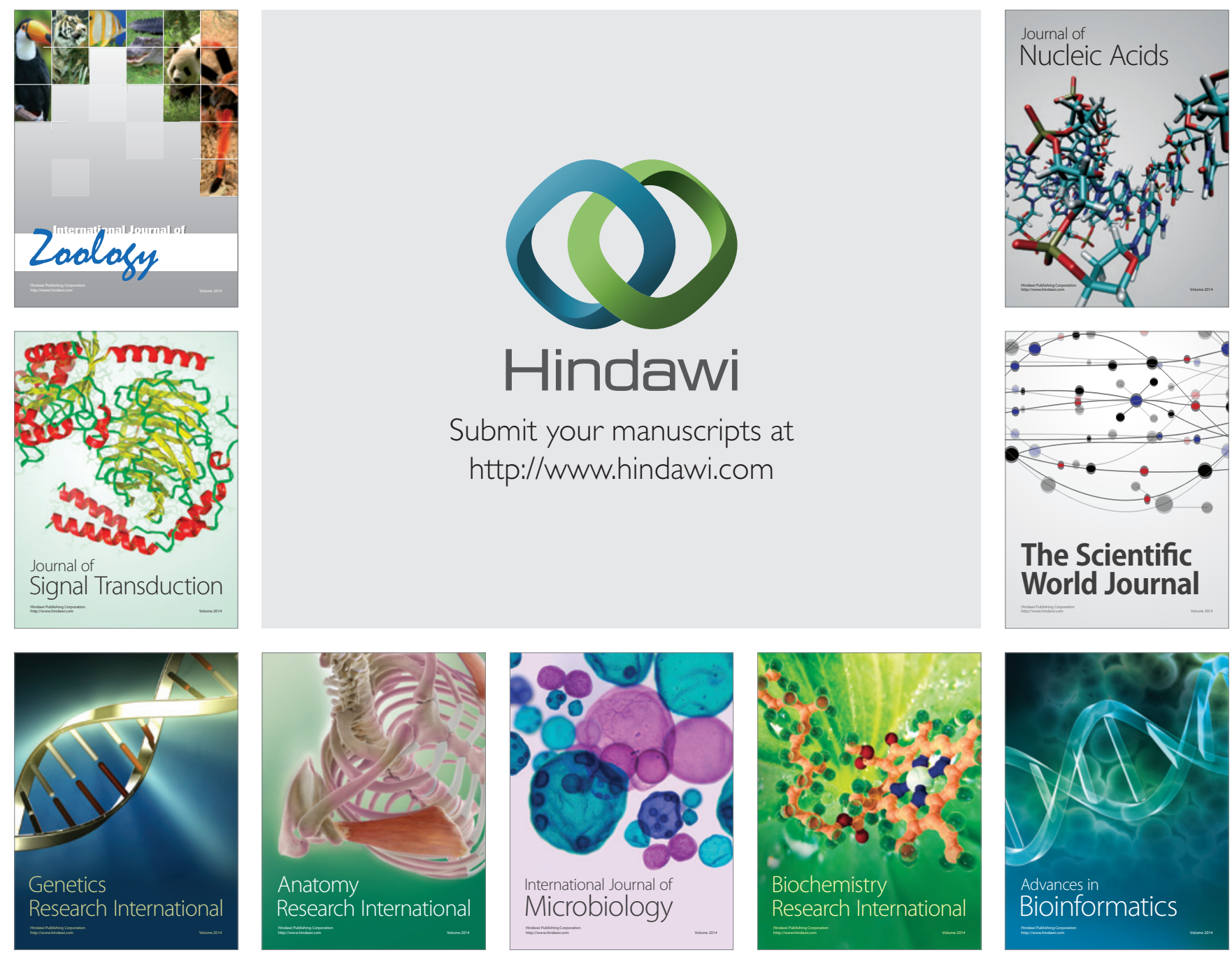

The Scientific World Journal
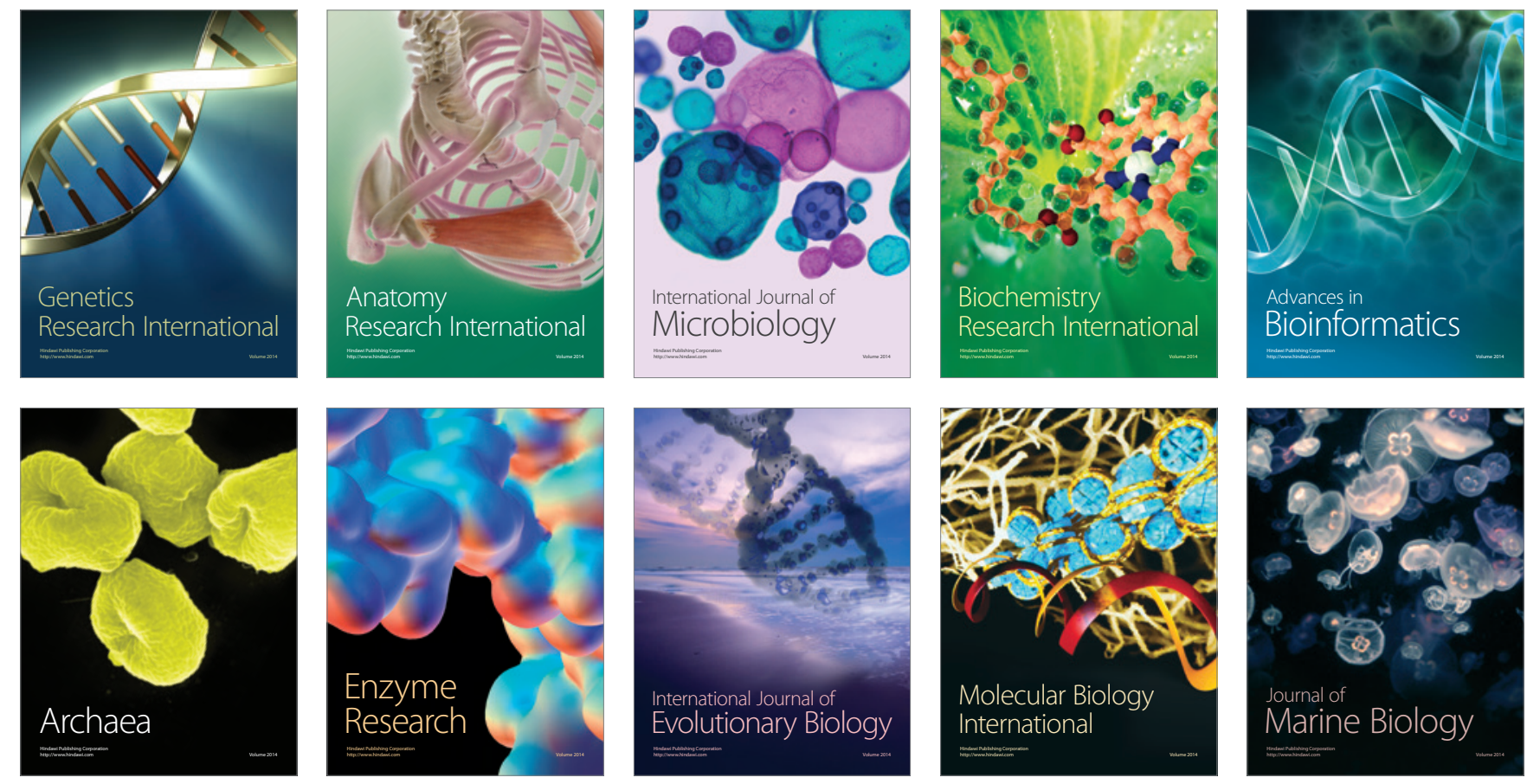